\title{
鯉の餌料と乞ての未利用原料比較試羷
}

\author{
On the Effect of Some Unutilized Materials
}

Added to the Basic Food for the Carp Culture

$$
\begin{gathered}
\text { 小山 }- \text { H. KOYAMA } \\
\text { (水蓝試驗場 上田分場) }
\end{gathered}
$$

\section{（水蓅試驗場 上四分場）}

In order to examine the effect of hitherto unutilized materials for young carp feeding, four kinds of artifficially mixed food were made.

A. The basic food (40\% of fishmeal, $40 \%$ of Gammarus and $20 \%$ of Ricebran.)

B. $40 \%$ of mulbery leaves was added to $60 \%$ of $A$.

C. $40 \%$ of walnut leaves added to $60 \%$ of $\mathrm{A}$.

D. $40 \%$ of spiked water milfoil was added to $60 \%$ of $\mathrm{A}$.

They were used for feeding young carps, of almost the same size reared in the four experimental ponds of the same size and under the same condition, for fourty four days, July 29 September $10,1948$.

The result was as follws:

On the average, the carps fed with A grow most quickly, then come those fed with $B$, those fed with $\mathrm{C}$, and lastly come those fed with $\mathrm{D}$, and they increased the weight of body $24.1 \%, 13.6 \% 7.4 \%$ and $6.2 \%$ respectively.

But regarding the total sum of the fish production, due to the survival rate of fish, $B$ is the best, $C$ is the $2 \mathrm{nd}, \mathrm{D}$ is the $3 \mathrm{rd}$ and $\mathrm{A}$ is the last; the survival rates are at $90 \%$, $75 \%, 70 \%$ and $60 \%$ respectively.

According to the above result, the food value in fish culture must be concluded not only on the growth rate of individual fish, but also on the survival rate of rearing fish or on the total sum of fish production.

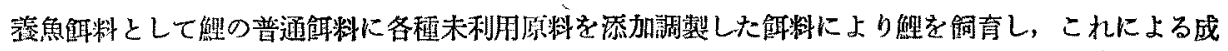
長度墄耗率等につき試䲆した結果を報告する。

試驗方法：（亿）試驗池は長さ $5.30 \mathrm{~m}$, 门 $0.90 \mathrm{~m}$, 樑さ $0.80 \mathrm{~m}$ 面樻 $4.70 \mathrm{~m}^{2}$ の矩形池悉使用

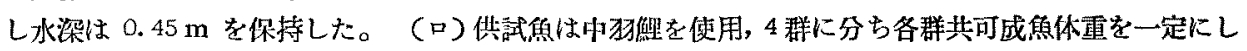

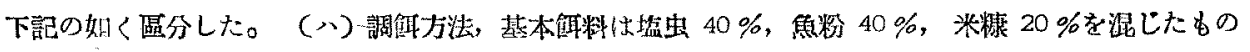

筇 1 表群別留 分

\begin{tabular}{|c|c|c|c|c|c|}
\hline \multirow{2}{*}{ 群 } & \multicolumn{2}{|c|}{ 飰料 配 合割 合 } & \multirow{2}{*}{ 試 魚 } & \multirow{2}{*}{ 供試鯰総体電 } & \multirow{2}{*}{ 平均体雷 } \\
\hline & 基本慨料 & 添加躡糊 & & & \\
\hline 桑 葉 添 加 群 & $60 \%$ & $40 \%$ & 20 屁 & $3100 \mathrm{gr}$ & $155.0 \mathrm{gr}$ \\
\hline くるみ葉添加群 & 60 & 40 & 20 & 3100 & 155.0 \\
\hline ほさきのふささも添加群 & 60 & 40 & 21 & 3100 & 147.6 \\
\hline 対照群（基本慨料） & 100 & - & 20 & 3100 & 155.0 \\
\hline
\end{tabular}

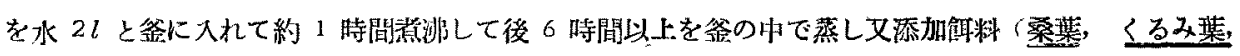
(昭和 23 年 4 月 7 日受理) 水浑試驗埸策績 第 60 号。 


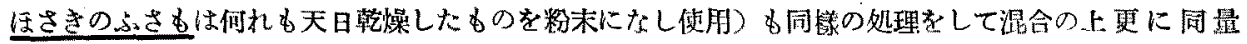

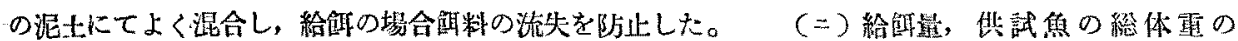

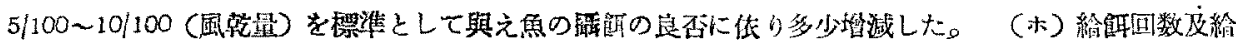

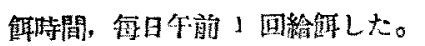

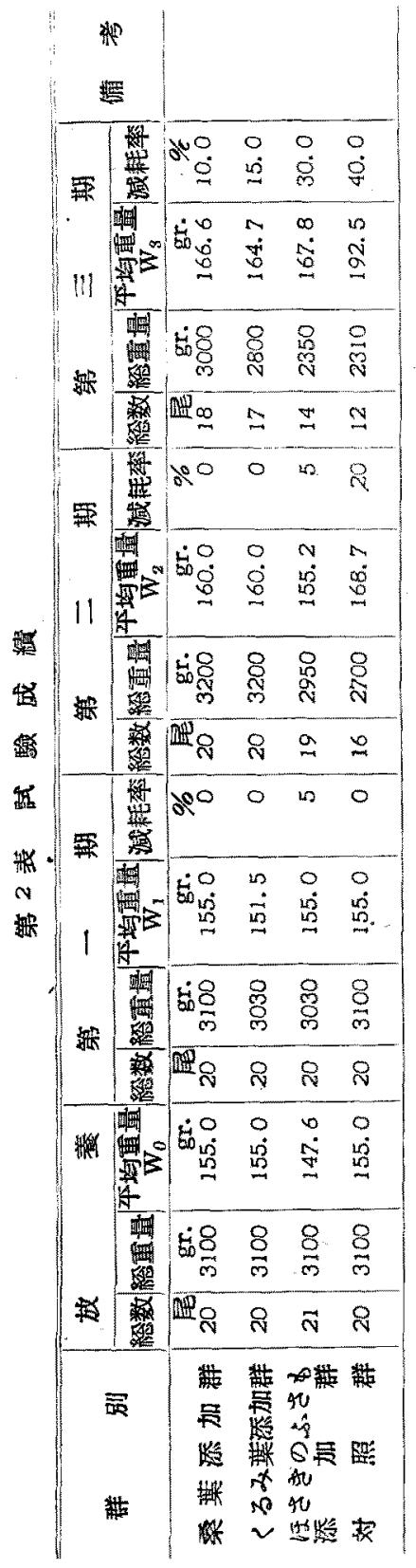

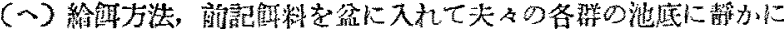
洮めて置いた。（ト）試驗期間，7月29日に着手し，9月 10 日に終了した。この間試驗終了時泛に 3 回取揚げて湘定した。 郎古第1 期末は 8 月 12 日, 第 2 期末は 8 月 27 日, 第3 期 末は9月11 日に取揚げて测定した。

第 2 表の各群各期の平均体重及減粍椊を図示すれば第 1 图及

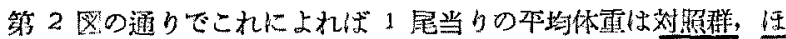

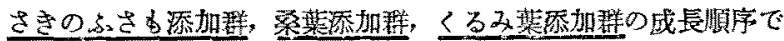

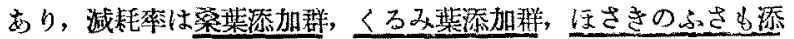
加群，及び対照群の㮌序に大であつた。

$$
\begin{aligned}
& \text { 第一圆 各群別各期比於计万平均体而比較 } \\
& \text { I 桑集添加数 } \\
& \text { II くるみ菜添加群 } \\
& \text { III ほさきのSさも源加群 } \\
& \text { IV 対 照 群 }
\end{aligned}
$$

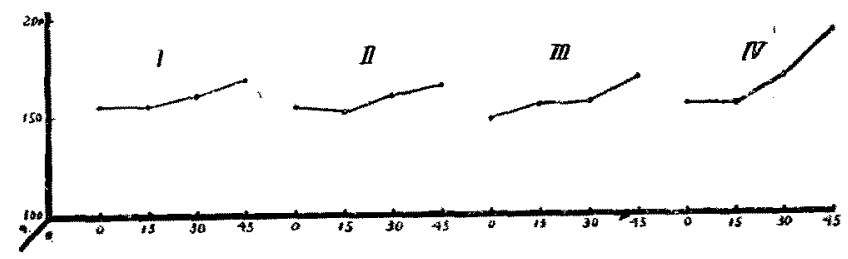

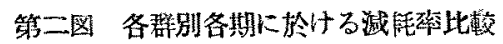

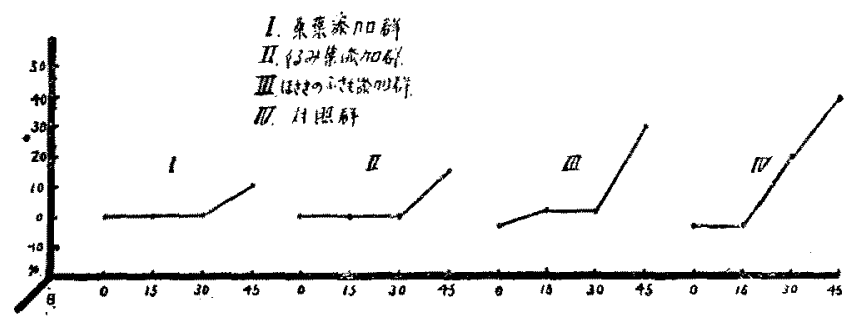

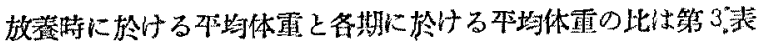
兹第 3 図の通りである。

第 3 表站算 3 図上り镍れば個体平均增重率は対照群最大て

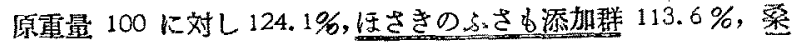

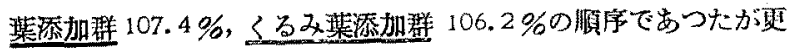

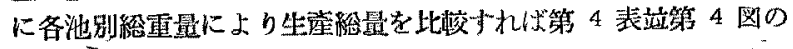

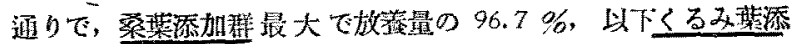


第 3 表 触料別做休平均增重率の比較

\begin{tabular}{|c|c|c|c|c|}
\hline 碓 & $\frac{W_{1}}{W_{0}} \times 100$ & $\begin{array}{l}W_{2} \\
W_{0}\end{array} \times 100$ & $\frac{W_{3}}{W_{0}} \times 100$ & 倩 \\
\hline 繠 禁 添 加 群 & 100.0 & 103.2 & 107.4 & 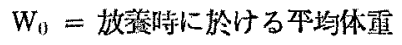 \\
\hline くる2葉添加群 & 97.7 & 103.2 & 106.2 & $\mathrm{~W}_{1}$ =第一期末に於ける年均体重 \\
\hline 㭱さきのふさむ添加群 & 105.0 & 105.1 & 113.6 & $\mathrm{~W}_{2}=$ 第二期未に於ける乎均体電 \\
\hline 照 & 100.0 & 108.8 & 124.1 & $\mathrm{~W}_{3}=$ 第三期末に於的る对均体雨 \\
\hline
\end{tabular}

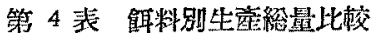

\begin{tabular}{|c|c|c|c|c|}
\hline 别 & I & II & III & 䓱 \\
\hline 桑 藮 添 加 群 & .100 .0 & 103.2 & 96.7 & \\
\hline くるみ藮湑加群 & 97.7 & 103.2 & 90.8 & \\
\hline ほさきのふざも添加群 & 100.0 & 95.1 & 75.8 & - \\
\hline 対照照 & 100.0 & 87.0 & 74.5 & \\
\hline
\end{tabular}

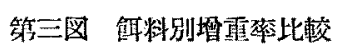

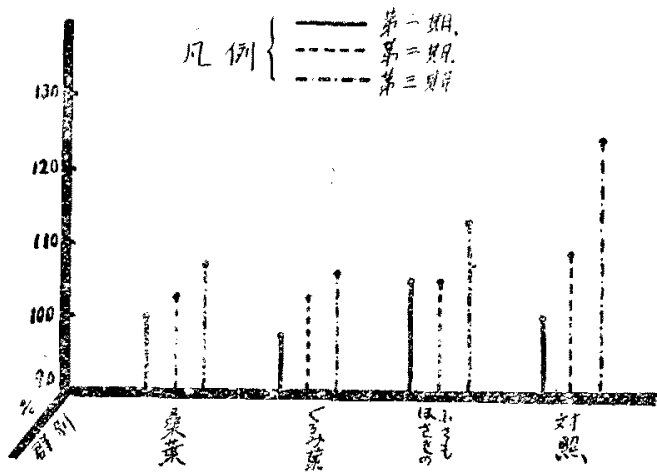

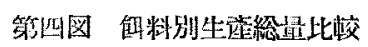

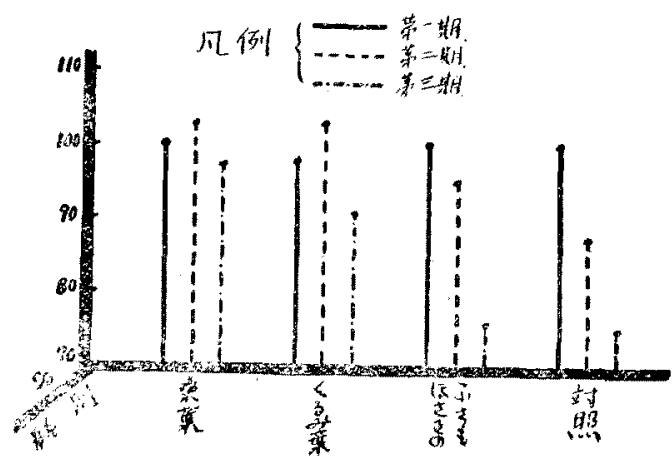

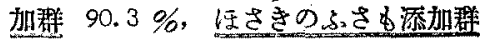
$75.8 \%$, 対照群 $74.5 \%$ ，の順序て對照 壁が尤も不良であつた。

以上の結果を結合して考察寸れは佃体 增雷の良否は池中現在量の密度に基因才 るるのと見られる。何故ならば沲中減耗 率大なる㖐恬ど個休增重が大であつたか らで岁るだから慨料の艮否は單に個休

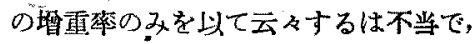

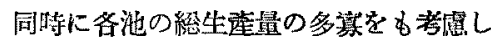
て制断すべきであると思われる。從つて

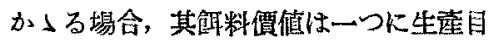
的にようて決定さるが帘当のよ.5に思わ れるから妶では何れとも断定せず只今回 の試駔結果の及を報告する次第である。 借考：期料單偠 (Kgr. 当り) 瀂粉 5.87 冈, 盐虫 8.00 円, 米慷 1.40 円,

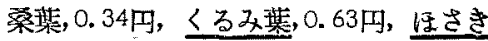

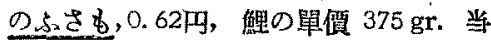
り60 円の制とすると，第 5 表に伡り

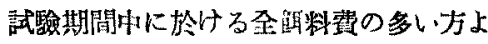
り記せば対照群，任さきのふささむ添加群， くる2禁源加群, 桑菜添加群の順序であ りこれによる鯆の生產县(金額に換算) 
第 5 表経济関 係

\begin{tabular}{|c|c|c|c|c|}
\hline 稀 & 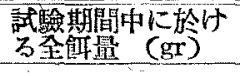 & 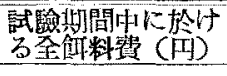 & 生筮量 (问) & $\begin{array}{l}375 \mathrm{gr} \text { 当 } 50 \\
\text { 椇筑 } \\
\text { (阬) }\end{array}$ \\
\hline 桑 琵 添 加 群 & 8160 & 33.28 & 33. 40 & 0.02 \\
\hline くるみ禁潶加群 & 3160 & 36.75 & 21.29 & -40.30 \\
\hline ほさきのぶさも添加群 & 7910 & 40.73 & 45.02 & 5.07 \\
\hline 照 & 7660 & 44.64 & 72.00 & 22.51 \\
\hline
\end{tabular}

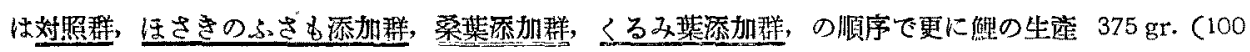

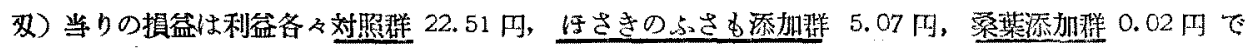
くるみ葉添加群は 40.30 円の損失ですつた。

第 6 表 尌駼期間中に於计る锶测

\begin{tabular}{|c|c|c|c|c|c|c|c|c|c|c|c|c|}
\hline \multirow{2}{*}{ 區 } & & \multirow{2}{*}{ 分 } & \multicolumn{2}{|c|}{ 天。 } & 候 & \multicolumn{2}{|l|}{ 氯 } & 泳 & \multicolumn{2}{|l|}{ 水 } & 溫 & \multirow{2}{*}{ 降水量 } \\
\hline & & & 晴 & 雯 & 雨 & 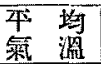 & 最 商 & 最 低 & $\begin{array}{ll}\text { 平均 } \\
\text { 水留 }\end{array}$ & 最 高 & 最 低 & \\
\hline 第 & - & 期 & 12日 & 3 & - & $28.7^{\circ} \mathrm{C}$ & $35.4^{\circ} \mathrm{C}$ & $12.7^{\circ} \mathrm{C}$ & $24.7^{\circ} \mathrm{C}$ & $26.3^{\circ} \mathrm{C}$ & $22.5^{\circ} \mathrm{C}$ & $\begin{array}{l}\text { m.m. } \\
11.8\end{array}$ \\
\hline 第 & $=$ & 期 & 14 & 1 & - & 27.7 & 34.7 & 11.8 & 25.7 & 26.3 & 22.8 & 62.1 \\
\hline 第 & $\equiv$ & 期 & 7 & 8 & - & 26.2 & 33.1 & 10.0 & 22.3 & 25.2 & 20.8 & 57.2 \\
\hline
\end{tabular}

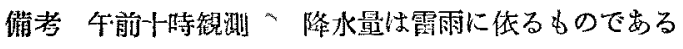

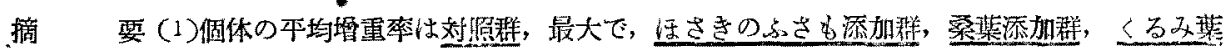

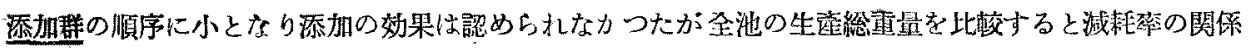
から桑葉添加群最大で，〈るみの葉添加群，ほさきのふさも添加群これに次ざいづれも添加の効果を示

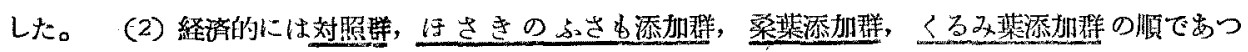

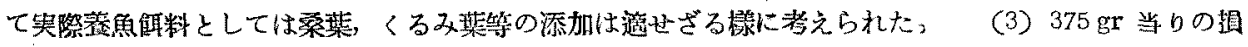

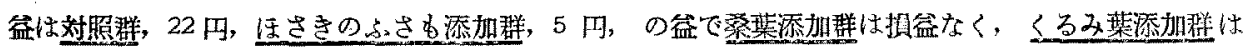
40 円の損であつた。

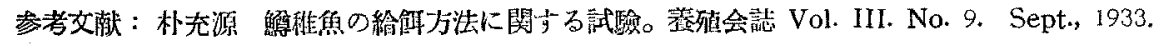

